\title{
Is microbial biomass measurement by the chloroform fumigation extraction method biased by experimental addition of $\mathrm{N}$ and $\mathrm{P}$ ?
}

\author{
Taiki Mori ${ }^{(1-2)}$, \\ Senhao Wang ${ }^{(1-3)}$, \\ Cong Wang ${ }^{(1-3)}$, \\ Jiangming $\mathrm{Mo}^{(1)}$, \\ Wei Zhang ${ }^{(1)}$
}

\begin{abstract}
The chloroform fumigation extraction (CFE) method determines microbial biomass carbon $(M B C)$ or nitrogen $(M B N)$ by calculating the increase in extractable carbon $(C)$ or nitrogen $(\mathrm{N})$ due to microbial lysis during chloroform fumigation. In China, many studies have focused on the impacts of $\mathrm{N}$ and phosphorus (P) addition on soil MBC and MBN in forest ecosystems, where substantial atmospheric $\mathbf{N}$ deposition has strongly acidified soils. The addition of nutrients may alter the extraction process applied in the CFE method, potentially influencing the $M B C$ and $M B N$ determined by the CFE method independently of the actual microbial biomass. In this study, we tested whether the MBC and MBN determined by the CFE method were biased by the experimental addition of $\mathrm{N}$ and $\mathrm{P}$ in strongly acidified Chinese forest soils by adding $\mathrm{N}$ and $\mathrm{P}$ to the soils immediately before chloroform fumigation, which should not affect the actual microbial biomass. $P$ addition significantly elevated the dissolved organic carbon (DOC) content, especially after fumigation, while $\mathrm{N}$ addition significantly reduced the dissolved nitrogen (DN) content. The added $\mathrm{N}$ was subtracted using blank samples without soil. However, the altered DOC and DN contents did not affect the MBC and MBN contents determined by the CFE method. In conclusion, our study suggests that the CFE is a relatively robust method to test the impacts of nutrient addition on microbial biomass in the strongly acidified soils of Chinese forests. We also suggested that: (i) even if a fertilization experiment results in an elevated DOC content following $P$ addition, it does not necessarily indicate a stimulation of DOC production by $\mathrm{mi}$ crobes; and (ii) the soil adsorption capacity or the strength of microbial $\mathrm{N}$ uptake during the extraction procedure applied in the CFE method may affect the determination of MBN by influencing the DN extraction efficiency.
\end{abstract}

Keywords: Chloroform Fumigation Extraction, Microbial Biomass, Nitrogen, Phosphorus, Soil, Tropical Forest

dissolved nitrogen (DN) extracted by $0.5 \mathrm{M}$ $\mathrm{K}_{2} \mathrm{SO}_{4}$, during chloroform fumigation. During fumigation, microbial cells lyse and a portion of the dead microbial constituents are transformed into extractable components through enzymatic autolysis. The CFE method assumes that the increases in DOC or DN are in proportion to the soil microbial biomass, and therefore the microbial biomass can be calculated using conversion factors (Jenkinson et al. 2004). This

(1) Key Laboratory of Vegetation Restoration and Management of Degraded Ecosystems, South China Botanical Garden and Guangdong Provincial Key Laboratory of Applied Botany, Chinese Academy of Sciences, Guangzhou, 510650 (China); (2) Kyushu Research Center, Forestry and Forest Products Research Institute, FFPRI, Kurokami 4-11-16, Kumamoto, 8600862 (Japan); (3) University of Chinese Academy of Sciences, Beijing 100049 (China)

@ Wei Zhang (zhangwei@scbg.ac.cn)

Received: Feb 13, 2020 - Accepted: Jul 07, 2021

Citation: Mori T, Wang S, Wang C, Mo J, Zhang W (2021). Is microbial biomass measurement by the chloroform fumigation extraction method biased by experimental addition of $\mathrm{N}$ and $\mathrm{P}$ ? iForest 14: 408-412. - doi: 10.3832/ifor3374-014 [online 2021-09-04]

method enables a relatively accurate and quick determination of soil microbial biomass.

Researchers have investigated the impacts of nutrient addition, such as nitrogen $(\mathrm{N})$ and phosphorus (P), on soil microbial biomass. This has enabled an evaluation of the impacts of anthropogenic nutrient loading into soils, such as atmospheric nutrient deposition or nutrient fertilization, on soil microbial biomass (Treseder 2008, Liu \& Greaver 2010). Additionally, microbial nutrient limitations have been determined (Liu et al. 2012, Liu et al. 2015, Turner \& Wright 2014, Mori et al. 2018). In China, many studies have focused on the impacts of the substantial increases in atmospheric $\mathrm{N}$ deposition, which have strongly acidified forest soils (Lu et al. 2014), and the subsequent imbalanced input of $\mathrm{N}$ and $\mathrm{P}$ into ecosystems that is consequently occurring (Du et al. 2016). The CFE method has been generally used to examine the effects of $\mathrm{N}$ and $\mathrm{P}$ addition on soil microbial biomass (Treseder 2008, Liu \& Greaver 2010, Liu et al. 2012, Turner \& Wright 2014, Fanin et al. 2015, Mori et al. 2016).

Several studies have reported methodological weaknesses of the CFE method. 
For example, Alessi et al. (2011) suggested that chloroform can adsorb onto the soil during fumigation, especially onto the clay minerals, causing an increase in DOC and hence an overestimation of the MBC in clay-rich soils (Rotbart et al. 2017). It has also been demonstrated that soil moisture can affect the determination of MBC (Ross 1989). Despite these methodological problems can under- or overestimate soil MBC and $M B N$, it is assumed that the impacts of nutrient addition on soil microbial biomass can be tested relatively robustly, because both nutrient-amended soils and a nonamended control are similarly influenced by these methodological problems.

However, the robustness of the CFE method for testing the impacts of nutrient addition on soil microbial biomass has not been fully examined. Added nutrients may alter the extraction process applied in the CFE method, potentially influencing the $M B C$ and MBN determined by the method independently of the actual microbial biomass. It is possible that the changes in soil $\mathrm{pH}$ through nutrient addition affect the microbial biomass determined by the CFE method, because soil $\mathrm{pH}$ can affect the extraction efficiency of $\mathrm{DOC}$ by $\mathrm{K}_{2} \mathrm{SO}_{4}$ (Haney et al. 1999, 2001). Müller et al. (2003) reported that $\mathrm{NH}_{4}{ }^{+}$immobilization may occur during fumigation. The determination of MBN could then be affected by nutrient addition through changes in DN immobilization (Hall \& Matson 1999, 2003) during fumigation. Changes in soil adsorption capacity may also affect the determination of $M B C$ or MBN. It has been reported that the extracted DOC content can be physicochemically affected by $\mathrm{P}$ fertilization (Mori et al. 2018), because $P$ has a higher affinity with soil surfaces than DOC (Kaiser \& Zech 1996) and $P$ can desorb DOC at the mineral surfaces (Hobara et al. 2016). If a portion of the DOC flushed out by chloroform fumigation (i.e., increase in $\mathrm{DOC}$ during fumigation) is adsorbed by soil (and $0.5 \mathrm{M} \mathrm{K}_{2} \mathrm{SO}_{4}$ does not extract all of the adsorbed DOC), $P$ addition could cause larger $M B C$ values by desorbing the adsorbed DOC.

The aim of this study was to test whether the MBC and MBN determined by the CFE method are biased by the experimental addition of $\mathrm{N}$ and $\mathrm{P}$ in strongly acidified Chinese forest soils. By adding $\mathrm{N}$ and $\mathrm{P}$ immediately before fumigation, we evaluated the CFE method-dependent impacts of nutrient addition on microbial biomass determination. Because the addition of $\mathrm{N}$ and $\mathrm{P}$ immediately before fumigation should not affect the actual microbial biomass (i.e., microbes have no time to change their biomass), any changes in the MBC and MBN should be caused by the impacts of $\mathrm{N}$ and $\mathrm{P}$ addition on the CFE method (e.g., alterations to the DOC and DN extraction process).

\section{Materials and methods}

\section{Study sites}

Soil samples for the experiment were collected from six forests in China. Three of the six forest sites were located in the Dinghushan Biosphere Reserve (DHS; $23^{\circ}$ $10^{\prime} \mathrm{N}, 112^{\circ} 10^{\prime} \mathrm{E}-$ Mo et al. 2003, 2006): a primary monsoon evergreen broadleaf forest (BF), a secondary mixed pine/broadleaf forest (MF), and a planted Pinus massoniana forest (PM). Two forest sites were located in the Heshan National Field Research Station (HS; $22^{\circ} 34^{\prime} \mathrm{N}, 112^{\circ} 50^{\prime} \mathrm{E}-$ Zhang et al. 2012): a planted Acacia auriculiformis forest (AA) and a planted Eucalyptus urophylla forest (EU). The final site was a mixed deciduous forest (MDF) located in the Jigongshan National Nature Reserve (JGS; $31^{\circ} 46^{\prime}-31^{\circ} 52^{\prime} \mathrm{N}, 114^{\circ} 01^{\prime}-114^{\circ} 06^{\prime} \mathrm{E}$ Zhang et al. 2015). The annual average temperature is $21.0^{\circ} \mathrm{C}, 22.5^{\circ} \mathrm{C}$, and $15.2^{\circ} \mathrm{C}$ and the annual average precipitation is 1580 , 1927, and $1119 \mathrm{~mm}$ in DHS, HS, and JGS, respectively (Huang \& Fan 1982, Zhang et al. 2015, Shao et al. 2017). The soils in DHS, HS, and JGS are a lateritic red earth formed from sandstone (Mo et al. 2003, Zhou et al. 2018), an Acrisol (Zhu et al. 2015), and a yellow brown soil (Zhang et al. 2015), respec- tively. The basic characteristics of the study sites are summarized in Tab. 1. All six forests have received large amounts of atmospheric $\mathrm{N}$ deposition (Mo et al. 2006, Zhang et al. 2012, 2015, Mao et al. 2017, Zhou et al. 2018).

\section{Experimental setup and chloroform fumigation}

Surface soil samples $(0-10 \mathrm{~cm})$ were collected from subplots at the six forest sites using soil cores (three, three, and four subplots in DHS, HS, and JGS, respectively). Soil samples taken from the same site were combined, and six replicates were prepared for the experiment. We sieved the soil samples through a 2-mm sieve after removing the fine roots and coarse organic matter. Sieved soil samples (6 g) were placed in bottles (glass bottles for fumigated soils and plastic bottles for unfumigated soils) and $1.5 \mathrm{~mL} \mathrm{~N}(500 \mu \mathrm{g} \mathrm{N}$ per 1.5 $\mathrm{mL}$ solution in the form of $\mathrm{NH}_{4} \mathrm{NO}_{3}$ ) or $\mathrm{P}$ ( $500 \mu \mathrm{g} P$ per $1.5 \mathrm{~mL}$ solution in the form of $\mathrm{KH}_{2} \mathrm{PO}_{4}$ ) were added. The final concentrations of the added $\mathrm{N}$ and $\mathrm{P}$ (around $100 \mu \mathrm{g}$ $\mathrm{N}$ and $\mathrm{P}$ per $\mathrm{g}$ soil) were in a similar range to that of previous laboratory experiments where nutrient concentrations were decided based on the nutrient doses in the field (Duah-Yentumi et al. 1998, Cleveland et al. 2002, Ilstedt \& Singh 2005, Mori et al. 2013a, 2013b). Controls without $\mathrm{N}$ or $\mathrm{P}$ addition were prepared in the same manner by adding pure water. Blanks without soils were also prepared for both fumigated and unfumigated samples. The DOC and DN before the fumigation ( $D O C_{b e f}$ and $D N_{b e f}$ ) were extracted immediately after the addition of the $\mathrm{N}$ or $\mathrm{P}$ solutions by shaking the soils with $30 \mathrm{~mL} 0.5 \mathrm{M} \mathrm{K}_{2} \mathrm{SO}_{4}$ for $30 \mathrm{~min}$. Fumigated samples were placed in a vacuum desiccator and exposed to chloroform vapor for $24 \mathrm{~h}$ (Vance et al. 1987). The DOC and $\mathrm{DN}$ after the fumigation $\left(\mathrm{DOC}_{\mathrm{aft}}\right.$ and $\mathrm{DN}_{\mathrm{aft}}$ ) were extracted in the same manner as $\mathrm{DOC}_{\text {bef }}$ and $\mathrm{DN}_{\text {bef. }}$. The $\mathrm{MBC}$ and $\mathrm{MBN}$ were then calculated by subtracting $\mathrm{DOC}_{\text {bef }}$ from $\mathrm{DOC}_{\text {aft }}$ and $\mathrm{DN}_{\mathrm{bef}}$ from $\mathrm{DN}_{\mathrm{aft}}$, respec-

Tab. 1 - Selected basic characteristics (mean \pm standard error) of the six forest sites investigated. Data collection and source: (a) measured in 2015 (from Zheng et al. 2018); (b) measured in 2015 (from Zheng et al. 2017); (c) measured in Dec 2011 (from Zhu et al. 2015); (d) measured in Jul 2018 (from Liu et al. 2020); (e-f) measured in the present study. Sample size: (a-d) $n=3$; (e) $n=5$; (f) $n=1$. Sites: (BF) primary monsoon evergreen broadleaf forest; (MF) secondary mixed pine/broadleaf forest; (PM) planted Pinus massoniana forest; (AA) planted Acacia auriculiformis forest; (EU) planted Eucalyptus urophylla forest; (MDF) mixed deciduous forest. Variables: (DOC) dissolved organic carbon; (DN) dissolved nitrogen. Soil samples for chemical analysis were taken from 0-10 cm depths.

\begin{tabular}{|c|c|c|c|c|c|c|}
\hline \multirow{2}{*}{ Characteristics } & \multicolumn{6}{|c|}{ Sites } \\
\hline & $\mathrm{BF}$ & MF & PM & AA & EU & MDF \\
\hline Soil organic $\mathrm{C}\left(\mathrm{g} \mathrm{kg}^{-1}\right)$ & $40.0 \pm 4.2^{\mathrm{a}}$ & $32.1 \pm 4.0^{b}$ & $23.3 \pm 1.6^{b}$ & $23.8 \pm 1.7^{c}$ & $18.5 \pm 0.4^{c}$ & $63 \pm 13^{d}$ \\
\hline Soil total $\mathrm{N}\left(\mathrm{g} \mathrm{kg}^{-1}\right)$ & $2.9 \pm 0.5^{a}$ & $2.0 \pm 0.3^{b}$ & $1.4 \pm 0.2^{b}$ & $2.0 \pm 0.1^{c}$ & $1.5 \pm 0.2^{c}$ & $3.4 \pm 0.5^{\mathrm{d}}$ \\
\hline Soil available $\mathrm{P}\left(\mathrm{mg} \mathrm{kg}^{-1}\right)$ & $2.1 \pm 0.4^{\mathrm{a}}$ & $1.0 \pm 0.3^{b}$ & $1.5 \pm 0.3^{b}$ & $2.5 \pm 0.2^{c}$ & $2.1 \pm 0.1^{c}$ & $6.9 \pm 2.0^{d}$ \\
\hline $\mathrm{DOC}\left(\mu \mathrm{g} \mathrm{C} \mathrm{g}^{-1}\right)$ & $220.7 \pm 3.6^{e}$ & $154.4 \pm 2.5^{\mathrm{e}}$ & $208.0 \pm 4.4^{\mathrm{e}}$ & $275.6 \pm 3.5^{\mathrm{e}}$ & $297.9 \pm 3.6^{\mathrm{e}}$ & $135.0 \pm 2.0^{\mathrm{e}}$ \\
\hline $\mathrm{DN}\left(\mu \mathrm{g} C \mathrm{~g}^{-1}\right)$ & $29.9 \pm 1.9^{\mathrm{e}}$ & $17.9 \pm 1.0^{\mathrm{e}}$ & $25.9 \pm 1.8^{\mathrm{e}}$ & $38.5 \pm 1.1^{\mathrm{e}}$ & $41.8 \pm 2.2^{\mathrm{e}}$ & $25.4 \pm 0.8^{\mathrm{e}}$ \\
\hline Soil pH $\left(\mathrm{H}_{2} \mathrm{O}\right)$ & $3.53^{f}$ & $3.68^{f}$ & $3.6^{f}$ & $3.4^{f}$ & $3.65^{f}$ & $4.25 \pm 0.10^{d}$ \\
\hline Soil water content & $0.24^{f}$ & $0.18^{f}$ & $0.22^{f}$ & $0.23^{f}$ & $0.27^{f}$ & $0.13^{f}$ \\
\hline
\end{tabular}



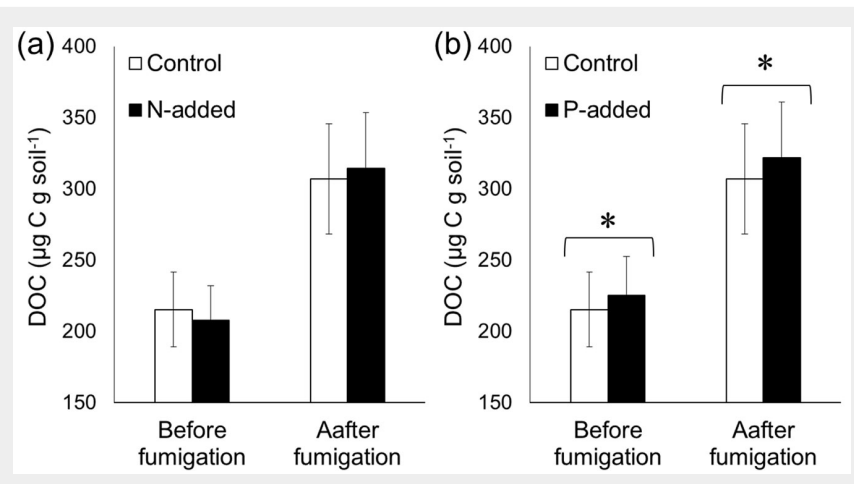

Fig. 1 - Effects of experimental (a) $\mathrm{N}$ addition and (b) P addition on the dissolved organic carbon (DOC) content before and after chloroform fumigation. The DOC was extracted by $0.5 \mathrm{M}$ $\mathrm{K}_{2} \mathrm{SO}_{4}$ after 30 min of shaking. Error bars indicate the standard error of data from six sites. Statistical significance was determined by a paired $t$-test. $(*): p<0.05 ;(* *): p<0.01$.
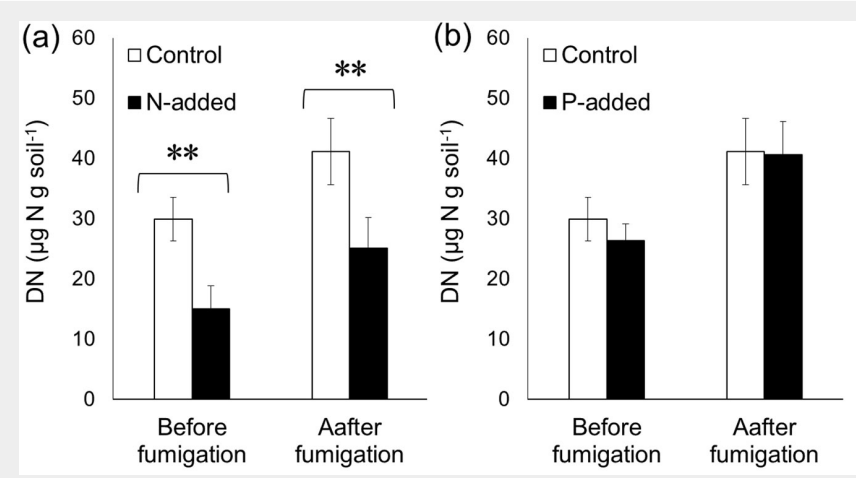

Fig. 2 - Effects of experimental (a) $\mathrm{N}$ addition and (b) P addition on the dissolved nitrogen (DN) content before and after chloroform fumigation. The DN was extracted by $0.5 \mathrm{M} \mathrm{K}_{2} \mathrm{SO}_{4}$ after $30 \mathrm{~min}$ of shaking. Error bars indicate the standard error of data from six sites. Statistical significance was determined by a paired t-test. $\left(^{*}\right): p<0.05 ;(* *): p<0.01$. tively. A conversion factor of 0.45 was used for calculating both MBC and MBN (Jenkinson et al. 2004). The DOC and DN were measured with a total organic carbon analyzer (TOC-5000 ${ }^{\oplus}$, Shimadzu, Japan). Soil $\mathrm{pH}\left(\mathrm{H}_{2} \mathrm{O}\right.$ ) (soil to water ratio 1:2.5) was measured using unfumigated soils. We had only five replicates for the $\mathrm{pH}$ analysis because we failed to analyze JGS soils.

\section{Statistics}

A paired $t$-test was used to determine the statistical significance of differences between control soils and $\mathrm{N}$ - or P-amended soils. This statistical analysis was used because our main purpose was to confirm that $\mathrm{N}$ and $\mathrm{P}$ addition did not affect the $M B C$ and $M B N$ determination by the CFE method (i.e., repeating a $t$-test increases type 1 errors, and therefore a more robust result could be obtained if there were no statistical differences). If the paired $t$-test revealed any significant differences, an additional analysis was performed using a linear mixed effect model. All statistical analy- ses were performed using $R$ version 4.0.2 (R Core Team 2020).

\section{Results}

Effects of $N$ and $P$ addition on DOC and DN

The DOC and DN contents in our study sites ranged from 130 to $300 \mu \mathrm{g} \mathrm{C} \mathrm{g} \mathrm{soil-1}$ and from 15 to $45 \mu \mathrm{g} \mathrm{N}$ g soil-1, respectively. Chloroform fumigation caused a large elevation in both the $\mathrm{DOC}$ and $\mathrm{DN}$ contents (by $\sim 100 \mu \mathrm{g} C$ g soil- ${ }^{-1}$ and $10 \mu \mathrm{g} \mathrm{N}$ g soil ${ }^{-1}$, respectively - Fig. 1, Fig. 2). $\mathrm{N}$ addition did not show any impact on the DOC content $\left(D_{\text {bef }}\right.$ or $\mathrm{DOC}_{\text {aft }}$ ) extracted by $0.5 \mathrm{M} \mathrm{K}_{2} \mathrm{SO}_{4}$ ( $p>0.05$ - Fig. 1a). By contrast, a paired $t$ test demonstrated that $P$ addition significantly elevated the DOC content $(p<0.05$ - Fig. 1b). According to a linear mixed effect model analysis, the impact of $\mathrm{P}$ addition was statistically significant on the DO$C_{\text {aft }}$ content $(p<0.01)$, but not on the $\mathrm{DOC}_{\text {bef }}$ content $(p=0.26)$. Both the paired t-test and linear mixed effect model analy- sis demonstrated that $\mathrm{N}$ addition significantly decreased both the $\mathrm{DN}_{\text {bef }}$ and $\mathrm{DN}_{\text {aft }}$ contents ( $p<0.01$ - Fig. $2 a)$. Note that the amount of added $\mathrm{N}$ was subtracted using the blank samples. $P$ addition did not affect the DN content ( $p>0.05-$ Fig. $2 b)$.

\section{Effects of $N$ and $P$ addition on $M B C$, $\mathrm{MBN}$, and $\mathrm{pH}$}

$\mathrm{N}$ addition did not affect the $M B C$ content determined by the CFE method ( $p>0.05-$ Fig. 3a), which was consistent with the fact that neither $\mathrm{DOC}_{\text {bef }}$ nor $\mathrm{DOC}_{\text {aft }}$ were affected by $\mathrm{N}$ addition. Similarly, the MBN content was not influenced by $\mathrm{P}$ addition ( $p>$ 0.05 - Fig. 4b). Despite the altered DN content by $\mathrm{N}$ addition, the MBN content was not affected by $\mathrm{N}$ addition ( $p>0.05-$ Fig. $4 a)$. $P$ addition did not affect the MBC content ( $p>0.05-$ Fig. $3 b$ ), although $P$ addition significantly increased the $\mathrm{DOC}_{\mathrm{aft}}$ content.

Both the paired $t$-test and linear mixed effect model analyses demonstrated that $\mathrm{N}$ addition significantly decreased soil $\mathrm{pH}(\mathrm{p}<$
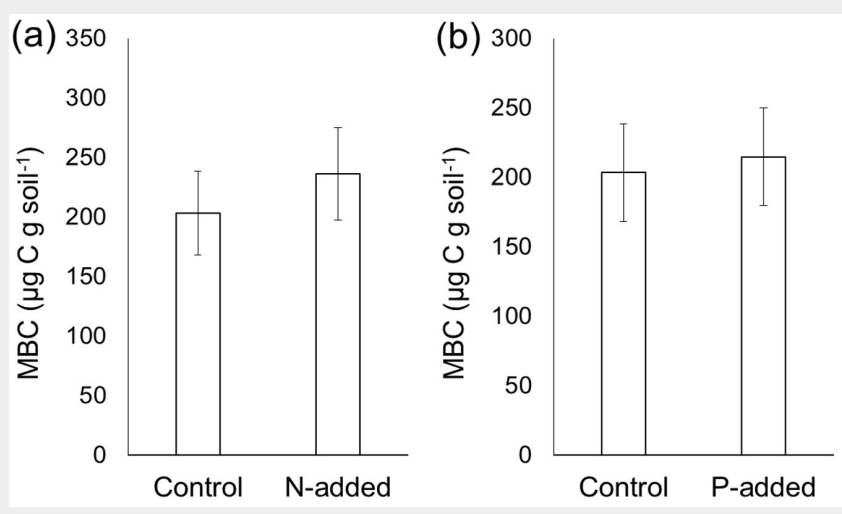

Fig. 3 - Effects of experimental (a) $\mathrm{N}$ addition and (b) $\mathrm{P}$ addition on the microbial biomass carbon (MBC) content before and after chloroform fumigation. Error bars indicate the standard error of data from six sites. A paired $t$-test did not reveal significant differences $(p>0.05)$.
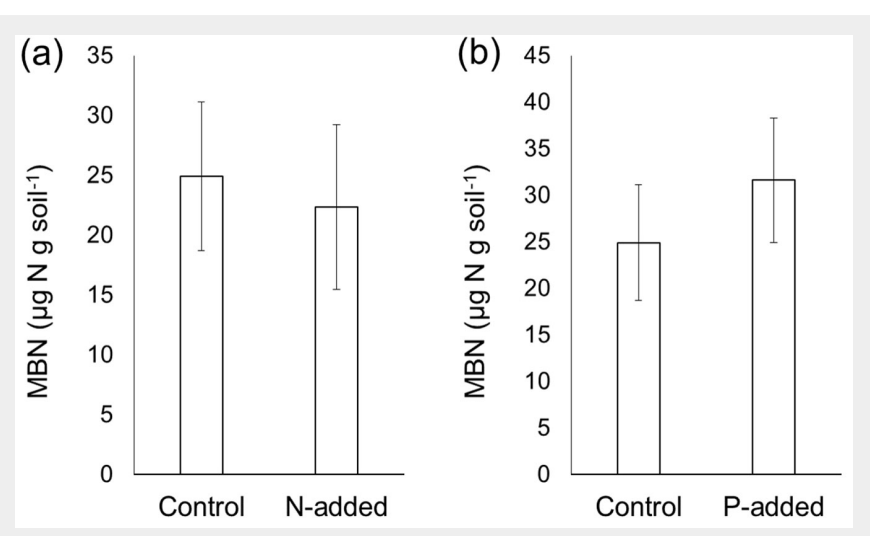

Fig. 4 - Effects of experimental (a) $\mathrm{N}$ addition and (b) $\mathrm{P}$ addition on the microbial biomass nitrogen (MBN) content before and after chloroform fumigation. Error bars indicate the standard error of data from six sites. A paired t-test did not reveal significant differences $(p>0.05)$. 


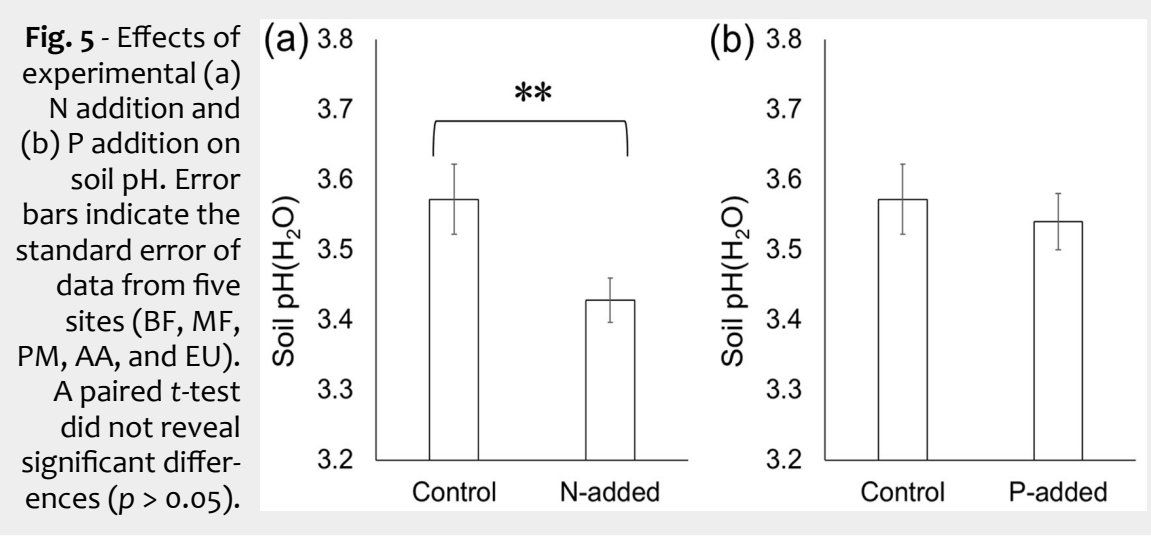

0.01 - Fig. 5a). Meanwhile, $\mathrm{P}$ addition did not have a significant influence $(p>0.05-$ Fig. 5b).

\section{Discussion}

\section{Effects of $\mathrm{N}$ and $\mathrm{P}$ addition on $\mathrm{DOC}$ and DN}

The decrease in the DN content following $\mathrm{N}$ addition in both the unfumigated and fumigated soils indicated that a portion of the added $\mathrm{N}\left(\mathrm{NH}_{4} \mathrm{NO}_{3}\right)$ was adsorbed by the soil or immobilized by microbes (Fig. 2a). It has been suggested that microbes could reduce the DN content during the extraction process (Rousk \& Jones 2010). This is important because it indicates that the soil adsorption capacity or the strength of microbial $\mathrm{N}$ immobilization may affect the DN extraction efficiency during the extraction procedure applied in the CFE method, influencing the MBN calculation. If this is the case, the recovery efficiency of the flush of DN during fumigation should be taken into account when calculating the MBN. Further studies are required to investigate this.

We also found that $\mathrm{P}$ addition elevated the DOC content (especially $\mathrm{DOC}_{\text {aft }}-$ Fig. $1 b)$. This was probably because the DOC adsorbed at the mineral surface (part of which was not extracted by $0.5 \mathrm{M} \mathrm{K}_{2} \mathrm{SO}_{4}$ ) was desorbed by P (Mori et al. 2018). Kaiser \& Zech (1996) performed sorption experiments where $\mathrm{H}_{2} \mathrm{PO}_{4}^{-}$had a higher affinity to soil than DOC. Hobara et al. (2016) demonstrated that extracting organic $C$ using a phosphate solution provided around 10 times more $\mathrm{C}$ than the use of $\mathrm{KCl}$ or water as an extractant, indicating that $\mathrm{P}$ has a strong ability to extract organic $C$ from soils. Thus, we attributed the increased DOC content to the desorption of DOC by the added $\mathrm{P}$. Changes in soil $\mathrm{pH}$ following $\mathrm{P}$ addition may have also caused the higher DOC content in P-amended soils (Haney et al. 2001), but this was less likely because $P$ addition did not change soil $\mathrm{pH}\left(\mathrm{H}_{2} \mathrm{O}\right)$ significantly (Fig. 5b), and the decrease in soil $\mathrm{pH}$ in $\mathrm{N}$-amended soils (Fig. 5a) did not affect the DOC content (Fig. 1a). The higher DOC content in P-amended soils in our study suggested that the impacts of $P$ fertilization on DOC content should be carefully interpreted in fertilization studies, be- cause the elevated DOC content following $P$ addition does not necessarily indicate stimulated DOC production by microbes.

\section{Effects of $N$ and $P$ addition on $M B C$ and MBN}

By adding $\mathrm{N}$ and $\mathrm{P}$ immediately before fumigation, we conducted tests to determine whether the $M B C$ and $M B N$ measured by the CFE method were biased by the experimental addition of $\mathrm{N}$ and $\mathrm{P}$ in strongly acidified Chinese forest soils. Our results demonstrated that the $\mathrm{MBC}$ and MBN contents were not significantly biased. Despite the increase in the DOC content following $P$ addition (Fig. $1 \mathrm{~b}$ ) and reduced DN content following $\mathrm{N}$ addition (Fig. 2a), neither $M B C$ (calculated as the differences between $\mathrm{DOC}_{\text {bef }}$ and $\mathrm{DOC}_{\mathrm{aft}}$ ) nor MBN (calculated as the differences between $\mathrm{DN}_{\text {bef }}$ and $\mathrm{DN}_{\mathrm{aft}}$ ) was affected by $\mathrm{N}$ or $\mathrm{P}$ addition. The reduced $\mathrm{DN}_{\text {aft }}$ content following $\mathrm{N}$ addition did not differ from the reduced $\mathrm{DN}_{\text {bef }}$ content (Fig. 2a), which consequently caused the MBN content to be unaffected by $\mathrm{N}$ addition (Fig. 4a). Similarly, the elevated DO$C_{a f t}$ content following $P$ addition did not differ from the elevated $D O C_{\text {bef }}$, resulting in an insignificant difference in the $M B C$ between P-amended soils and the control without $P$ addition (Fig. 3 b). Overall, our results suggest that the CFE method is a relatively robust method to test the impacts of nutrient addition on microbial biomass in the strongly acidified soils of Chinese forests. However, to generalize our results, more studies are needed, especially in soils with a high $\mathrm{pH}$.

\section{Conclusions}

By testing whether the $\mathrm{N}$ or $\mathrm{P}$ addition immediately before fumigation affected the results of a microbial biomass determination by the CFE method, we evaluated the robustness of the CFE method for determining the impacts of $\mathrm{N}$ and $\mathrm{P}$ addition on microbial biomass $\mathrm{C}$ and $\mathrm{N}$ in the strongly acidified soils of Chinese forests. We found that $\mathrm{P}$ addition significantly elevated the DOC content (especially $\mathrm{DOC}_{\text {aft }}$ ); $\mathrm{N}$ addition significantly reduced the DN content; and the altered DOC and DN contents did not change the MBC or MBN contents determined by the CFE method. We concluded that CFE is a relatively robust meth- od to determine the impacts of nutrient addition on microbial biomass in the strongly acidified soils of Chinese forests. The results also suggest that even if a fertilization experiment revealed an elevated DOC content after $\mathrm{P}$ addition, it does not necessarily indicate $\mathrm{DOC}$ production by microbes. The soil adsorption capacity or strength of microbial $\mathrm{N}$ uptake during the extraction procedure applied in the CFE method may affect the determination of MBN by influencing the $\mathrm{DN}$ extraction efficiency.

\section{Acknowledgements}

TM conceived the research and wrote the draft of the manuscript, TM, SW, and CW performed experiment, JM and WZ established research sites, all of the authors joined the discussion of the research. We thank Mr Fu and Ms Hu for their support for our field work. This study was financially supported by National Natural Science Foundation of China (no. 42077311, no. 41731176), Grant-in-Aid for JSPS Postdoctoral Fellowships for Research Abroad (28-601), and a grant from the Sumitomo Foundation (153082).

\section{References}

Alessi DS, Walsh DM, Fein JB (2011). Uncertainties in determining microbial biomass $C$ using the chloroform fumigation-extraction method. Chemical Geology 280: 58-64. - doi: 10.1016/j. chemgeo.2010.10.014

Brookes PC, Landman A, Pruden G, Jenkinson DS (1985). Chloroform fumigation and the release of soil nitrogen: a rapid direct extraction method to measure microbial biomass nitrogen in soil. Soil Biology and Biochemistry 17: 837842. - doi: 10.1016/0038-0717(85)90144-0

Cleveland CC, Townsend AR, Schmidt SK (2002). Phosphorus limitation of microbial processes in moist tropical forests: evidence from shortterm laboratory incubations and field studies. Ecosystems 5: 680-691. - doi: 10.1007/s10021002-0202-9

Du E, De Vries W, Han W, Liu X, Yan Z, Jiang Y (2016). Imbalanced phosphorus and nitrogen deposition in China's forests. Atmospheric Chemistry and Physics 16: 8571-8579. - doi: 10.5194/acp-16-8571-2016

Duah-Yentumi S, Ronn R, Christensen S (1998). Nutrients limiting microbial growth in a tropical forest soil of Ghana under different management. Applied Soil Ecology 8: 19-24. - doi: 10.101 6/S0929-1393(97)00070-X

Fanin N, Hättenschwiler S, Schimann H, Fromin $\mathrm{N}$ (2015). Interactive effects of C, N and P fertilization on soil microbial community structure and function in an Amazonian rain forest. Functional Ecology 29: 140-150. - doi: 10.1111/1365-243 5.12329

Hall SJ, Matson PA (1999). Nitrogen oxide emissions after nitrogen additions in tropical forests. Nature 400: 152. - doi: 10.1038/22094

Hall SJ, Matson P (2003). Nutrient status of tropical rain forests influences soil $\mathrm{N}$ dynamics after $\mathrm{N}$ additions. Ecological Monographs 73: 107-129. - doi: 10.1890/0012-9615(2003)073[0107:NSOTR F]2.0.CO;2

Haney RL, Franzluebbers AJ, Hons FM, Zuberer 
DA (1999). Soil C extracted with water or $\mathrm{K}_{2} \mathrm{SO}_{4}$ : $\mathrm{pH}$ effect on determination of microbial biomass. Canadian Journal of Soil Science 79: 529 533. - doi: 10.4141/S99-011

Haney RL, Franzluebbers AJ, Hons FM, Hossner $\mathrm{LR}$, Zuberer DA (2001). Molar concentration of $\mathrm{K}_{2} \mathrm{SO}_{4}$ and soil $\mathrm{pH}$ affect estimation of extractable $\mathrm{C}$ with chloroform fumigation-extraction. Soil Biology and Biochemistry 33 (11): 1501-1507. - doi: 10.1016/S0038-0717(01)00065-7

Hobara S, Kushida K, Kim Y, Koba K, Lee B-Y, Ae $\mathrm{N}$ (2016). Relationships among $\mathrm{pH}$, minerals, and carbon in soils from tundra to boreal forest across Alaska. Ecosystems 19 (6): 1092-1103. doi: 10.1007/s10021-016-9989-7

Huang ZF, Fan ZG (1982). The climate of Ding Hu Shan. Tropical and Subtropical Forest Ecosystem 1: 11-23.

Ilstedt U, Singh S (2005). Nitrogen and phosphorus limitations of microbial respiration in a tropical phosphorus-fixing acrisol (ultisol) compared with organic compost. Soil Biology and Biochemistry 37: 1407-1410. - doi: 10.1016/j.soil bio.2005.01.002

Jenkinson DS, Brookes PC, Powlson DS (2004). Measuring soil microbial biomass. Soil Biology and Biochemistry 36: 5-7. - doi: 10.1016/j.soilbio. 2003.10.002

Kaiser K, Zech W (1996). Nitrate, sulfate, and biphosphate retention in acid forest soils affected by natural dissolved organic carbon. Journal of Environmental Quality 25 (6): 13251331. - doi: $10.2134 /$ jeq1996.0047242500250006 $0022 \mathrm{x}$

Liu L, Greaver TL (2010). A global perspective on belowground carbon dynamics under nitrogen enrichment. Ecology Letters 13: 819-828. - doi: 10.1111/j.1461-0248.2010.01482.x

Liu L, Gundersen P, Zhang T, Mo J (2012). Effects of phosphorus addition on soil microbial biomass and community composition in three forest types in tropical China. Soil Biology and Biochemistry 44: 31-38. - doi: 10.1016/j.soilbio.2011. 08.017

Liu L, Gundersen P, Zhang W, Zhang $\mathrm{T}$, Chen $\mathrm{H}$, Mo $J$ (2015). Effects of nitrogen and phosphorus additions on soil microbial biomass and community structure in two reforested tropical forests. Scientific Reports 5: 14378 . - doi: 10.103 8/srep14378

Liu T, Mao P, Shi L, Eisenhauer N, Liu S, Wang X, He X, Wang Z, Zhang W, Liu Z, Zhou L, Shao Y, Fu S (2020). Forest canopy maintains the soil community composition under elevated nitrogen deposition. Soil Biology and Biochemistry 143: 107733. - doi: 10.1016/j.soilbio.2020.107733

Lu X, Mao Q, Gilliam FS, Luo Y, Mo J (2014). Nitrogen deposition contributes to soil acidification in tropical ecosystems. Global Change Biology 20: 3790-3801. - doi: 10.1111/gcb.12665 Mao Q, Lu X, Wang C, Zhou K, Mo J (2017). Responses of understory plant physiological traits to a decade of nitrogen addition in a tropical reforested ecosystem. Forest Ecology and
Management 401: 65-74. - doi: 10.1016/j.foreco. 2017.06.047

Mo J, Brown S, Peng S, Kong G (2003). Nitrogen availability in disturbed, rehabilitated and mature forests of tropical China. Forest Ecology and Management 175: 573-583. - doi: 10.1016/ S0378-1127(02)00220-7

Mo J, Brown S, Jinghua X, Fang Y, Li Z (2006). Response of litter decomposition to simulated $\mathrm{N}$ deposition in disturbed, rehabilitated and mature forests in subtropical China. Plant and Soil. 135-161. - doi: 10.1007/s11104-005-5446-7

Mori T, Ohta S, Ishizuka S, Konda R, Wicaksono A, Heriyanto J, Hardjono A (2013a). Effects of phosphorus addition with and without ammonium, nitrate, or glucose on $\mathrm{N}_{2} \mathrm{O}$ and $\mathrm{NO}$ emissions from soil sampled under Acacia mangium plantation and incubated at $100 \%$ of the waterfilled pore space. Biology and Fertility of Soils 49. - doi: 10.1007/s00374-012-0690-5

Mori T, Ohta S, Ishizuka S, Konda R, Wicaksono A, Heriyanto J, Hardjono A (2013b). Effects of phosphorus and nitrogen addition on heterotrophic respiration in an Acacia mangium plantation soil in South Sumatra, Indonesia. Tropics 22: 83-87. - doi: 10.1111/j.1747-0765.2010.00501.x Mori T, Yokoyama D, Kitayama K (2016). Contrasting effects of exogenous phosphorus application on $\mathrm{N}_{2} \mathrm{O}$ emissions from two tropical forest soils with contrasting phosphorus availability. SpringerPlus 5: 1237. - doi: 10.1186/s400 64-016-2587-5

Mori T, Lu X, Aoyagi R, Mo J (2018). Reconsidering the phosphorus limitation of soil microbial activity in tropical forests. Functional Ecology 32: 1145-1154. - doi: 10.1111/1365-2435.13043

Müller C, Stevens RJ, Laughlin RJ, Ottow JCG, Jäger HJ (2003). Ammonium immobilisation during chloroform fumigation. Soil Biology and Biochemistry 35: 651-665. - doi: 10.1016/So0380717(03)00014-2

R Core Team (2020). R: a language and environment for statistical computing. Statistical, R Foundation for Computing, Vienna, Austria. [online] URL: http://www.r-project.org/

Ross DJ (1989). Estimation of soil microbial C by a fumigation-extraction procedure: Influence of soil moisture content. Soil Biology and Biochemistry 21: 767-772. - doi: 10.1016/0038-0717 (89)90168-5

Rotbart $\mathrm{N}$, Borisover $\mathrm{M}$, Bukhanovsky $\mathrm{N}$, Nasonova A, Bar-Tal A, Oren A (2017). Examination of residual chloroform interference in the measurement of microbial biomass $C$ by fumigation-extraction. Soil Biology and Biochemistry 111: 60-65. - doi: 10.1016/j.soilbio.2017.03.018

Rousk J, Jones DL (2010). Loss of low molecular weight dissolved organic carbon (DOC) and nitrogen (DON) in $\mathrm{H}_{2} \mathrm{O}$ and $0.5 \mathrm{M} \mathrm{K}_{2} \mathrm{SO}_{4}$ soil extracts. Soil Biology and Biochemistry 42: 23312335. - doi: 10.1016/j.soilbio.2010.08.017

Shao Y, Zhang W, Eisenhauer N, Liu T, Xiong Y, Liang C, Fu S (2017). Nitrogen deposition cancels out exotic earthworm effects on plant- feeding nematode communities. Journal of Animal Ecology 86: 708-717. - doi: 10.1111/1365-265 6.12660

Treseder KK (2008). Nitrogen additions and microbial biomass: a meta-analysis of ecosystem studies. Ecology Letters 11: 1111-1120. - doi: 10.111 1/j.1461-0248.2008.01230.x

Turner BL, Wright SJ (2014). The response of microbial biomass and hydrolytic enzymes to a decade of nitrogen, phosphorus, and potassium addition in a lowland tropical rain forest. Biogeochemistry 117: 115-130. - doi: 10.1007/s105 33-013-9848-y

Vance ED, Brookes PC, Jenkinson DS (1987). Microbial biomass measurement in forest soils: the use of the chloroform fumigation-incubation method in strongly acid soils. Soil Biology and Biochemistry 19: 697-702. - doi: 10.1016/ 0038-0717(87)90051-4

Xu X, Thornton PE, Post WM (2013). A global analysis of soil microbial biomass carbon, nitrogen and phosphorus in terrestrial ecosystems. Global Ecology and Biogeography 22: 737-749. doi: 10.1111/geb.12029

Zhang W, Zhu X, Liu L, Fu S, Chen H, Huang J, Lu $X$, Liu Z, Mo J (2012). Large difference of inhibitive effect of nitrogen deposition on soil methane oxidation between plantations with $\mathrm{N}$-fixing tree species and non- $\mathrm{N}$-fixing tree species. Journal of Geophysical Research: Atmospheres 117: GooN16. - doi: 10.1029/2012JG002094

Zhang W, Shen W, Zhu S, Wan S, Luo Y, Yan J, Wang K, Liu L, Dai H, Li P, Dai K, Zhang W, Liu Z, Wang F, Kuang Y, Li Z, Lin Y, Rao X, Li J, Zou B, Cai X, Mo J, Zhao P, Ye Q, Huang J, Fu S (2015). CAN Canopy addition of nitrogen better illustrate the effect of atmospheric nitrogen deposition on forest ecosystem? Scientific Reports 5: 11245. - doi: 10.1038/srep11245

Zheng M, Zhang W, Luo Y, Mori T, Mao Q, Wang S, Huang J, Lu X, Mo J (2017). Different responses of symbiotic nitrogen fixation to nitrogen addition between disturbed and rehabilitated subtropical forests. Science of the Total Environment 601-602: 1505-1512. - doi: 10.1016/j. scitotenv.2017.06.036

Zheng M, Zhang W, Luo Y, Li D, Wang S, Huang J, Lu X, Mo J (2018). Stoichiometry controls asymbiotic nitrogen fixation and its response to nitrogen inputs in a nitrogen-saturated forest. Ecology 99 (9): 2037-2046. - doi: 10.1002/ecy. 2416

Zhou K, Lu X, Mori T, Mao Q, Wang C, Zheng M, Mo H, Hou E, Mo J (2018). Effects of long-term nitrogen deposition on phosphorus leaching dynamics in a mature tropical forest. Biogeochemistry 138 (2): 215-224. - doi: 10.1007/s10533018-0442-1

Zhu X, Chen H, Zhang W, Huang J, Fu S, Liu Z, Mo $J$ (2015). Effects of nitrogen addition on litter decomposition and nutrient release in two tropical plantations with $\mathrm{N}_{2}$-fixing vs. non- $\mathrm{N}_{2}-$ fixing tree species. Plant and Soil 399: 61-74. - doi: 10.1007/s11104-015-2676-1 